\title{
Influence of laboratory light sources on the wear characteristics of indirect composites
}

\author{
Masakazu HIRATA ${ }^{1}$, Hiroyasu KOIZUMI ${ }^{1,2}$, Naomi TANOUE², Tomohisa OGINO ${ }^{1}$, Mahoko MURAKAMI ${ }^{1}$ \\ and Hideo MATSUMURA ${ }^{1,2}$ \\ ${ }^{1}$ Department of Fixed Prosthodontics, Nihon University School of Dentistry, 1-8-13 Kanda-Surugadai, Chiyoda-ku, Tokyo 101-8310, Japan \\ ${ }^{2}$ Division of Advanced Dental Treatment, Dental Research Center, Nihon University School of Dentistry, 1-8-13 Kanda-Surugadai, Chiyoda-ku, Tokyo \\ 101-8310, Japan \\ ${ }^{3}$ Department of General Dentistry, Dental Division, Nagasaki University Hospital, 1-7-1 Sakamoto, Nagasaki 852-8501, Japan \\ Corresponding author, Hiroyasu KOIZUMI; E-mail: koizumi@dent.nihon-u.ac.jp
}

\begin{abstract}
The purpose of the current study was to evaluate the influence of light sources on the mechanical properties and wear characteristics of indirect composite materials. The two composite materials used were Estenia C\&B and Epricord. The three laboratory polymerization units used, of which the wavelength range was $400-500 \mathrm{~nm}$, were Hyper LII (two metal halide lamps of $4.82 \mathrm{~mW} / \mathrm{cm}^{2}$ ), $\alpha$-Light II (one halogen lamp and two fluorescent tubes of $3.60 \mathrm{~mW} / \mathrm{cm}^{2}$ ), and Labolight LV-II (three fluorescent tubes of $0.63 \mathrm{~mW} /$ $\mathrm{cm}^{2}$ ). Three-body wear test was performed using indirect composite plate specimens, a gold alloy antagonist, and a polymer slurry. Wear depths of Estenia C\&B polymerized with Hyper LII, $\alpha$-Light II, and Labolight LV-II were 5.7, 18.5, and 64.2 $\mu \mathrm{m}$ respectively, whereas those of Epricord were 12.9, 18.7, and $48.5 \mu \mathrm{m}$ respectively. Results showed that, after 100,000 cycles of localized loading, high-intensity light sources were effective in enhancing the wear resistance of both composite materials.
\end{abstract}

Keywords: Indirect composite, Light source, Wear, Hardness, Flexural strength

\section{INTRODUCTION}

For dental restorations, the occlusal surfaces, incisal edges, and cusps are typically made of casting alloy, tooth-colored material, or both. When selecting a dental restorative material, one key consideration is that its intraoral wear behavior is equivalent to that of enamel. This is because the durability of dental restorations under occlusal stresses in vivo remains characteristically unpredictable - owing to the unpredictable wear that arises from the occlusal interaction between a restorative material and the antagonist. If an excessively abrasionresistant restorative material is used, it would negatively affect the maxillomandibular relation and may induce abrasion of antagonists or destroy the periodontal tissues. If a non-wear resistant material is used for the occlusal surface, the anatomic form will collapse within a short period and likewise the masticatory function of the prosthetic restoration.

In the fabrication of single tooth restorations, fixed partial dentures, and superstructures of implantsupported dental prostheses, the use of laboratorypolymerized composite materials has increased considerably over the last decades. This trend can be attributed to improvements in handling characteristics as well as in the mechanical properties ${ }^{1-20)}$ of composite materials, especially in terms of abrasion or wear resistance ${ }^{1-16)}$. Similarly, indirect composites have also demonstrated improved characteristics - through clinical evaluations - when used as prosthetic veneering agents $^{21-27)}$.

Unlike casting alloys and ceramic materials, the post-polymerization properties of indirect composites vary considerably depending on the conditions under which the matrix monomers are polymerized - namely, type of laboratory polymerization unit, light intensity, distance between light source and material surface, exposure duration, and post-cure heat treatment ${ }^{17-20,28,29)}$. Although the wear of indirect composites has been extensively evaluated ${ }^{1-16)}$, information on the wear characteristics of indirect composites in relation to laboratory polymerization conditions remains scarce.

Apart from the wear characteristics of restorative materials, the surface texture of antagonists also plays a vital role in the wear of occlusal surfaces and tooth structure. Therefore, the aim of this study was to evaluate the effects of three laboratory polymerization units equipped with light sources of different intensity levels on the mechanical properties (Knoop hardness and flexural strength) and wear characteristics of two indirect composites, and the impact of these properties and characteristics on the wear height loss of gold alloy antagonist.

\section{MATERIALS AND METHODS}

\section{Materials and polymerization units}

Two light-activated composite materials were selected for this study: Estenia C\&B and Epricord (Kuraray Medical Inc., Tokyo, Japan). Both materials were designed for indirect restorations and fixed partial dentures. Estenia C\&B was composed of approximately $12 \%$ methacrylate monomers and $87.9 \%$ filler ${ }^{30)}$, while Epricord was approximately 24\% methacrylate monomers and $76.0 \%$ filler ${ }^{311}$. Shade $\mathrm{E} 1$ for the enamel portion was used for specimen preparation. For the 
Table 1 Materials and light polymerization units used in this study

\begin{tabular}{|c|c|c|c|}
\hline Material / Trade name & Manufacturer & Lot number & Composition (wt\%) \\
\hline \multicolumn{4}{|l|}{$\underline{\text { Indirect composite }}$} \\
\hline Estenia C\&B E1 & $\begin{array}{l}\text { Kuraray Medical Inc., } \\
\text { Tokyo, Japan }\end{array}$ & 0035AA & $\begin{array}{l}\text { UTMA, Methacrylate, } d l \text {-Camphorquinone, } \\
\text { Pigment, } 87.9 \text { Filler (Surface treated alumina } \\
\text { micro filler, Silanated glass ceramic filler), Others }\end{array}$ \\
\hline Epricord E1 & Kuraray Medical Inc. & 0104BA & $\begin{array}{l}\text { UTMA, TEGDMA, } d l \text {-Camphorquinone, Pigment, } \\
76.0 \text { Filler (Prepolymerized organic filler, } \\
\text { Silanated glass filler, Silanated colloidal silica), } \\
\text { Others }\end{array}$ \\
\hline \multicolumn{4}{|l|}{$\underline{\text { Casting alloy }}$} \\
\hline $\begin{array}{l}\text { Casting Gold M.C. } \\
\text { Type IV }\end{array}$ & GC Corp., Tokyo, Japan & 0702151 & $70 \mathrm{Au}, 8 \mathrm{Ag}, 16 \mathrm{Cu}, 2 \mathrm{Pt}, 3 \mathrm{Pd}$ \\
\hline Polymerization unit & & & Light source, wavelength, and exposure duration \\
\hline Hyper LII & $\begin{array}{l}\text { Toho Dental Products, } \\
\text { Saitama, Japan }\end{array}$ & 160908 & Metal halide lamps: $150 \mathrm{~W} \times 2,250-600 \mathrm{~nm}, 60 \mathrm{~s}$ \\
\hline$\alpha$-Light II & $\begin{array}{l}\text { J. Morita Corp., Suita, } \\
\text { Japan }\end{array}$ & 0040 & $\begin{array}{l}\text { Halogen lamp: } 360 \mathrm{~W} \times 1,400-600 \mathrm{~nm} \text {; } \\
\text { Fluorescent tubes: } 27 \mathrm{~W} \times 2,400-550 \mathrm{~nm}, 180 \mathrm{~s}\end{array}$ \\
\hline Labolight LV-II & GC Corp. & 20459 & Fluorescent tubes: $27 \mathrm{~W} \times 3,400-550 \mathrm{~nm}, 180 \mathrm{~s}$ \\
\hline
\end{tabular}

UTMA: Urethane tetramethacrylate; TEGDMA: Triethylene glycol dimethacrylate

antagonist, the selected material was ADA Type IV gold alloy (Casting Gold M.C. Type IV, GC Corp., Tokyo, Japan).

Three light polymerization units were examined in this study. For Hyper LII unit (Toho Dental Products, Saitama, Japan) ${ }^{28)}$, two metal halide lamps were used for the light source; for $\alpha$-Light II unit (J. Morita Corp., Suita, Japan) ${ }^{29)}$, a halogen lamp and two fluorescent tubes were used; for Labolight LV-II unit (GC Corp. ${ }^{29)}$, three fluorescent tubes were used. Table 1 summarizes the details concerning the composite materials, casting alloy, and polymerization units.

\section{Light intensity measurement}

The energy density (light intensity) of the three light polymerization units was determined by means of a spectroradiometer (USR-40D, Ushio Inc., Tokyo, Japan) equipped with a ND10 (1/10 neutral density) filter. For Hyper LII unit, the radiometer sensor was positioned 97 $\mathrm{mm}$ from the light source; for $\alpha$-Light II unit, the distance was $86 \mathrm{~mm}$; for Labolight LV-II unit, it was $65 \mathrm{~mm}$. For each measurement of each light polymerization unit, the reading was taken at 3 seconds after the start of light exposure. The mean value of eight replications, with pause intervals of five minutes, was calculated for two wavelength ranges: 400-500 $\mathrm{nm}$ and 200-800 $\mathrm{nm}$. In particular, the visible light wavelength range of 400-500 $\mathrm{nm}$ was reportedly effective for the polymerization of camphorquinone-initiated dental composites ${ }^{31)}$.

\section{Knoop hardness measurement}

Composite specimens were produced by inserting paste into a split polytetrafluoroethylene mold of $2 \mathrm{~mm}$ height and which had a cylindrical opening of $10 \mathrm{~mm}$ diameter. Covered with a piece of glass plate $(0.12-0.17 \mathrm{~mm}$ thickness; Micro Cover Glass, Matsunami Glass, Osaka, Japan), composite paste was polymerized according to the conditions shown in Table 1 for each of the three light polymerization units. After polymerization, the upper surface of each specimen was wet-ground with a series of silicon carbide papers (WetorDry Tri-M-ite, 3M Corp., St. Paul, MN, USA) and then polished with felt (TexMet 1500, Buehler Ltd., Lake Bluff, IL, USA) and a diamond suspension $(0.25 \mu \mathrm{m}$; MetaDi monocrystalline diamond suspension, Buehler Ltd.). All specimens were stored in $37^{\circ} \mathrm{C}$ distilled water for 24 hours.

To evaluate the Knoop hardness of two kinds of composites polymerized using three different polymerization units, hardness at the center of each composite specimen was measured using an ultra micro hardness tester (HMV-1, Shimadzu Corp., Kyoto, Japan). Seven specimens were tested for each combination of composite type and light polymerization unit. The test conditions were: a fixed load of $98.07 \mathrm{mN}$, loading rate at $1.41 \times 10^{-2} \mathrm{Ns}^{-1}$, and load holding time for 5 seconds.

\section{Flexural strength measurement}

For flexural strength measurement, seven specimens were prepared for each combination of composite type and light polymerization unit using a stainless steel mold $(25.0 \times 2.0 \times 2.0 \mathrm{~mm})$ placed over a polyester strip. 
After filling the mold to excess, the material surface was covered with a polyester strip and glass plate (0.12-0.17 mm thickness; Micro Cover Glass, Matsunami Glass) and compressed under a $4.9 \mathrm{~N}$ load to extrude excess material. Specimens were light-activated using one of the three polymerizing units shown in Table 1. After polymerization, specimen dimensions were measured using a digital caliper (Digimatic Caliper CD67-S PM, Mitsutoyo Corp., Kawasaki, Japan). Specimens were then stored in $37^{\circ} \mathrm{C}$ distilled water for 24 hours.

Three-point bending test was carried out using a mechanical testing device (Type 5567, Instron Corp., Canton, MA, USA) at a crosshead speed of $1.0 \mathrm{~mm} / \mathrm{min}$ and at a span of $20.0 \mathrm{~mm}$ between supports.

\section{Wear test}

Composite materials were packed into a stainless steel mold $(25.0 \times 18.0 \times 2.0 \mathrm{~mm})$ and covered with a piece of glass plate (0.12-0.17 mm thickness; Micro Cover Glass, Matsunami Glass). Specimens were light-activated using one of the three polymerizing units shown in Table 1. After polymerization, the glass plate was removed and polymerized specimen was embedded in an epoxy resin (Cold Mounting No. 105, Marumoto Struers K. K., Tokyo, Japan). This was followed by wet-grinding with a series of silicon carbide abrasive papers (\#800-2000, WetorDry Tri-M-ite, 3M Corp.) and polishing with felt (TexMet 1500, Buehler Ltd.) and alumina $(0.3 \mu \mathrm{m}$, Baikalox 0.3CR, Baikowski International Corp., Charlotte, NC, USA).

Plastic patterns to be used for antagonist specimens were prepared using a prefabricated resin material with a 1.7-mm-diameter point end (Vario-Kugel-Snap vks 1.7, Bredent GmbH \& Co. KG, Senden, Germany). The plastic patterns were invested in a cristobalite mold, and the gold alloy was cast in the mold. The cast antagonists were age-hardened and polished according to the manufacturer's specifications.

After storage in $37^{\circ} \mathrm{C}$ water for 24 hours, a plate specimen and antagonist were placed in a sliding wear test apparatus (K-317, Tokyo Giken Inc., Tokyo, Japan). The surface to be worn was submerged in a slurry composed of equivalent weight of reagent grade glycerol (99\%, Wako Pure Chemical Ind., Osaka, Japan) and poly(methyl methacrylate) (PMMA) spherical particles (Acron, GC Corp.). Wear test was performed with a $5.9 \mathrm{~N}$ vertical load and 100,000 reciprocal strokes of 3 mm stroke width (Fig. 1). Wear depth of the plate specimen and height loss of the antagonist were determined using a scanning laser microscope (1LM21W, Lasertec Corp., Yokohama, Japan).

\section{Scanning electron microscope observation}

Worn specimens were mounted on stubs, dried in a vacuum desiccator for 24 hours, and vacuum-deposited with osmium (HPC-1S, Vacuum Device Inc., Mito, Japan) for 30 seconds. The surfaces of the plate specimens and antagonists were observed using a scanning electron microscope (S-4300, Hitachi HighTechnologies, Tokyo, Japan) operated at $15 \mathrm{kV}$.

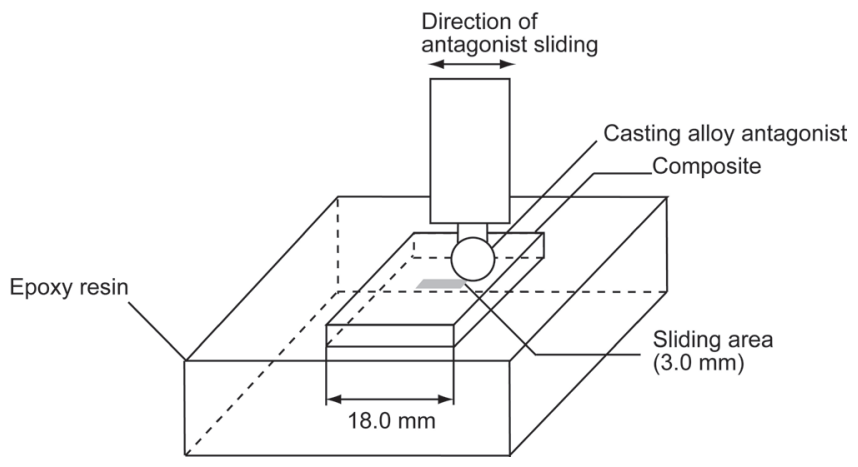

Fig. 1 Assembly used for sliding wear test.

\section{Statistical analysis}

Statistical analysis was carried out using SPSS software (Version 15.0 for Windows, SPSS Inc., Chicago, IL, USA). Average values, medians, and standard deviations of light intensity, Knoop hardness, flexural strength, wear depth of plate specimens, and height loss of the antagonist were calculated. The results were primarily analyzed using Kolmogorov-Smirnov test to test for normal distribution. When Kolmogorov-Smirnov analysis results did not show normal distribution for at least one category, the results were analyzed using Kruskal-Wallis test (SPSS 15.0). Based on KruskalWallis test results, Steel-Dwass non-parametric multiple comparisons (Kyplot 5.0, KyensLab Inc., Tokyo, Japan) were further applied to compare the differences among the polymerization units. In all the tests, $p$ values less than 0.05 were considered to be statistically significant.

\section{RESULTS}

\section{Light intensity}

Table 2 shows the light intensity values of the three light polymerization units, while Fig. 2 shows their spectral irradiance graphs. For the wavelength range of 400-500 $\mathrm{nm}$, the average value was $4.82 \mathrm{~mW} / \mathrm{cm}^{2}$ for Hyper LII, $3.60 \mathrm{~mW} / \mathrm{cm}^{2}$ for $\alpha$-Light II, and $0.63 \mathrm{~mW} / \mathrm{cm}^{2}$ for Labolight LV-II. For the wavelength range of 200-800 $\mathrm{nm}$, the value was $10.50 \mathrm{~mW} / \mathrm{cm}^{2}$ for Hyper LII, 8.87 $\mathrm{mW} / \mathrm{cm}^{2}$ for $\alpha$-Light II, and $0.79 \mathrm{~mW} / \mathrm{cm}^{2}$ for Labolight LV-II. Within each wavelength range, there were statistically significant differences in light intensity $(p<0.05)$ among the three light polymerization units.

\section{Knoop hardness}

When Kolmogorov-Smirnov test was applied on Knoop hardness results, no normal distribution $(p<0.05)$ was shown for Estenia C\&B composite polymerized with Hyper LII and Epricord polymerized with Labolight LV-II. Knoop hardness data were therefore analyzed using Steel-Dwass non-parametric multiple comparisons, and the results are shown in Table 3 .

For Estenia C\&B, highest hardness numbers (category 'a') were obtained when the composite was polymerized with Hyper LII and $\alpha$-Light II. Lowest 
hardness (category 'b') was obtained when it was polymerized with Labolight LV-II. For Epricord, highest hardness numbers (category 'c') were obtained when the
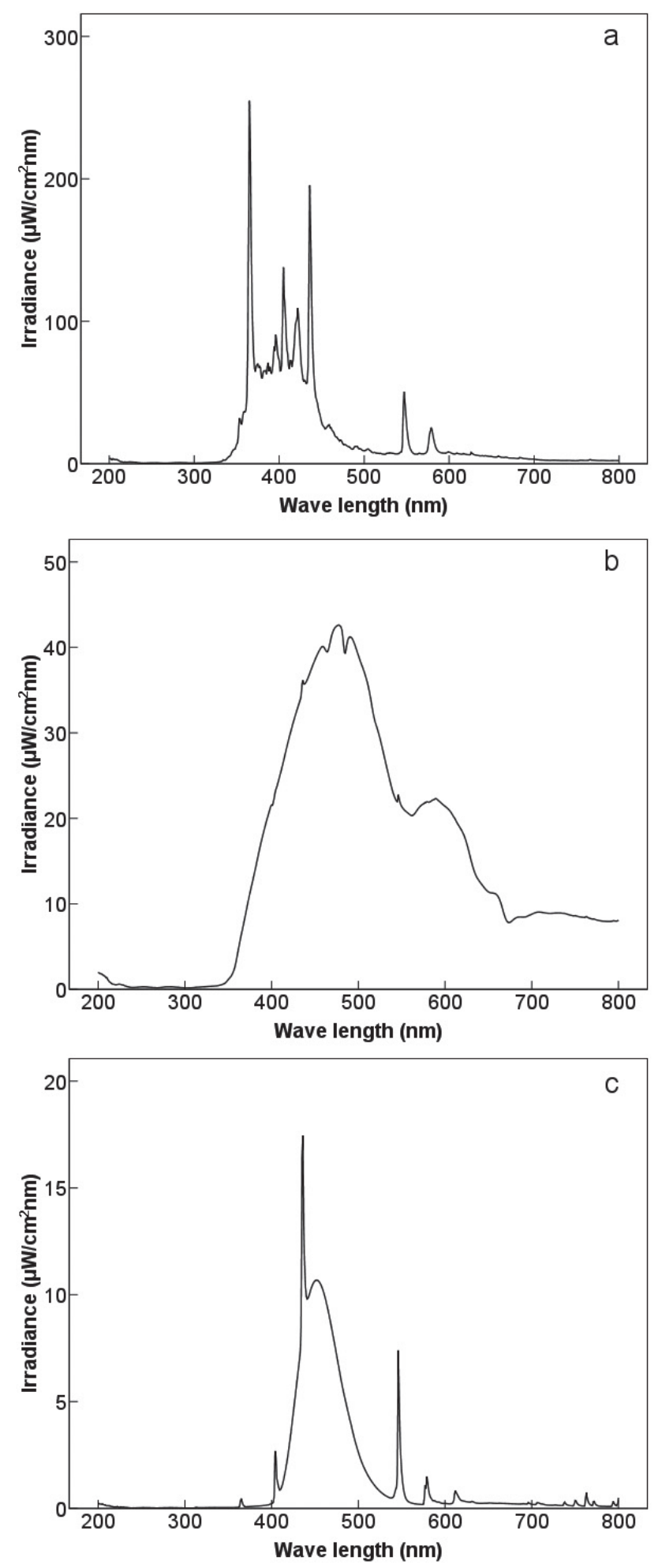

Fig. 2 Spectral irradiance graphs of: (a) Hyper LII; (b) $\alpha$-Light II; and (c) Labolight LV-II polymerization units. composite was polymerized with Hyper LII and $\alpha$-Light II. Similarly, lowest hardness (category 'd') was obtained when it was polymerized with Labolight LV-II.

\section{Flexural strength}

Table 4 shows the flexural strength results. Highest flexural strength was obtained when Estenia C\&B was polymerized with Hyper LII, followed by polymerization with $\alpha$-Light II and Labolight LV-II. For Epricord, highest flexural strength was obtained when it was polymerized with Hyper LII, followed by polymerization with $\alpha$-Light II and Labolight LV-II. For both composite materials, their flexural strength values among the three light polymerization units were significantly different from each other (categories 'e-g' and ' $\mathrm{h}-\mathrm{j}$ '; $p<0.05$ ).

\section{Wear test}

1. Wear depths of composite plate specimens

Kolmogorov-Smirnov tests applied on the wear test results of the two composites and gold alloy did not show normal distribution $(p<0.05)$ for wear of the plate specimens. Therefore, the wear test results of the two composites were further analyzed using Steel-Dwass non-parametric multiple comparisons. Table 5 presents the wear depths of the composite plate specimens.

For Estenia C\&B, smallest wear depth value was obtained when the composite was polymerized with Hyper LII, followed by polymerization with $\alpha$-Light II and Labolight LV-II. For Epricord, smallest wear depth value was obtained when it was polymerized with Hyper LII, followed by polymerization with $\alpha$-Light II and Labolight LV-II. For both composite materials, their wear depth values among the three light polymerization units were significantly different from each other (categories ' $\mathrm{k}-\mathrm{m}$ ' and ' $\mathrm{n}-\mathrm{p}$ '; $p<0.05$ ).

Figure 3 shows the worn surfaces of Estenia C\&B and Epricord composites abraded with gold alloy. For both composites, the specimens polymerized with Hyper LII exhibited the smoothest appearance, whereas those polymerized with Labolight LV-II showed considerably roughened surfaces.

2. Height loss of gold alloy antagonist

Table 6 shows the height loss results of Type IV gold alloy antagonist. With Estenia C\&B, the gold alloy exhibited the smallest height loss when the composite was polymerized using Hyper LII, but the greatest height loss when the composite was polymerized using Labolight LV-II. With Epricord, comparable height loss of the gold alloy was obtained when the composite was polymerized using either $\alpha$-Light II or Labolight LV-II, and the values were not statistically different (category ' $t$ '). However, height loss of the gold alloy was the greatest when Epricord was polymerized using Hyper LII.

Figure 4 shows the worn surfaces of Type IV gold alloy abraded with the two composite materials. Specimens with low height loss (Figs. 4a, 4e, and 4f) exhibited small, oval worn surfaces. 
Table 2 Light intensity values of three light polymerization units

\begin{tabular}{|c|c|c|c|c|}
\hline \multirow{2}{*}{ Polymerization unit } & \multirow{2}{*}{ L-S distance $(\mathrm{mm})$} & \multicolumn{3}{|l|}{ Light intensity $\left(\mathrm{mW} / \mathrm{cm}^{2}\right)$} \\
\hline & & Mean (SD) & Median & $\mathrm{IQR}$ \\
\hline & & \multicolumn{3}{|l|}{ Wavelength range: $400-500 \mathrm{~nm}$} \\
\hline Hyper LII & 97 & $4.82(0.09)$ & $4.82^{*}$ & 0.10 \\
\hline$\alpha$-Light II & 86 & $3.60(0.05)$ & $3.59^{* *}$ & 0.08 \\
\hline \multirow[t]{2}{*}{ Labolight LV-II } & 65 & $0.63(0.02)$ & $0.63^{* * *}$ & 0.03 \\
\hline & & \multicolumn{3}{|l|}{ Wavelength range: $200-800 \mathrm{~nm}$} \\
\hline Hyper LII & 97 & $10.50(0.17)$ & $10.46^{*}$ & 0.19 \\
\hline$\alpha$-Light II & 86 & $8.87(0.12)$ & $8.85^{* *}$ & 0.20 \\
\hline Labolight LV-II & 65 & $0.79(0.02)$ & $0.78^{* * *}$ & 0.04 \\
\hline
\end{tabular}

L-S distance: Distance between light source and the sensor; SD: standard deviation; IQR: Interquartile range;

Different superscript asterisks indicate presence of statistically significant difference $(p<0.05)$.

Table 3 Knoop hardness results

\begin{tabular}{|c|c|c|c|c|}
\hline \multirow{2}{*}{$\begin{array}{l}\text { Specimen } \\
\text { Polymerization unit }\end{array}$} & \multicolumn{3}{|c|}{ Knoop hardness number } & \multirow{2}{*}{ Statistical category } \\
\hline & Mean (SD) & Median & IQR & \\
\hline \multicolumn{5}{|l|}{ Estenia C\&B } \\
\hline Hyper LII & $283.0(56.1)$ & 312.0 & 116.0 & a \\
\hline$\alpha$-Light II & $228.6(17.5)$ & 222.0 & 37.0 & a \\
\hline Labolight LV-II & $156.9(30.5)$ & 167.0 & 40.0 & $\mathrm{~b}$ \\
\hline \multicolumn{5}{|l|}{ Epricord } \\
\hline Hyper LII & $63.5(10.3)$ & 64.8 & 20.8 & $\mathrm{c}$ \\
\hline$\alpha$-Light II & $57.1(5.8)$ & 59.9 & 10.7 & $\mathrm{c}$ \\
\hline Labolight LV-II & $45.6(7.1)$ & 46.3 & 13.7 & d \\
\hline
\end{tabular}

$n=7$; SD: Standard deviation; IQR: Interquartile range;

Statistical category: Different letters indicate that they are statistically different $(p<0.05)$.

Table 4 Flexural strength results

\begin{tabular}{|c|c|c|c|c|}
\hline \multirow{2}{*}{$\begin{array}{l}\text { Specimen } \\
\text { Polymerization unit }\end{array}$} & \multicolumn{3}{|c|}{ Flexural strength (MPa) } & \multirow{2}{*}{ Statistical category } \\
\hline & Mean (SD) & Median & IQR & \\
\hline \multicolumn{5}{|l|}{ Estenia C\&B } \\
\hline Hyper LII & $144.1(17.3)$ & 143.8 & 30.6 & $\mathrm{e}$ \\
\hline$\alpha$-Light II & $92.4(13.0)$ & 95.2 & 24.4 & $\mathrm{f}$ \\
\hline Labolight LV-II & $49.2(5.4)$ & 49.7 & 8.3 & $\mathrm{~g}$ \\
\hline \multicolumn{5}{|l|}{ Epricord } \\
\hline Hyper LII & $72.2(6.5)$ & 73.0 & 5.5 & $\mathrm{~h}$ \\
\hline$\alpha$-Light II & $35.5(3.8)$ & 34.4 & 5.3 & $\mathrm{i}$ \\
\hline Labolight LV-II & $13.3(3.1)$ & 11.7 & 4.8 & $\mathrm{j}$ \\
\hline
\end{tabular}

$n=7$; SD: Standard deviation; IQR: Interquartile range;

Statistical category: Different letters indicate that they are statistically different $(p<0.05)$.

\section{DISCUSSION}

\section{Laboratory light sources}

This study evaluated the wear characteristics of two indirect composite materials polymerized with different laboratory light polymerization units. Light intensity evaluation using two wavelength ranges revealed that
Labolight LV-II had the lowest light intensity among the three polymerization units - although it registered the shortest distance between its light source and the radiometer sensor. This result was probably attributable to the low-energy irradiance of the three fluorescent tubes. Specifically, irradiance of the fluorescent tubes was less than $20 \mu \mathrm{W} / \mathrm{cm}^{2} \mathrm{~nm}$ for both wavelength ranges. 
Table 5 Wear depths of composite plate specimens

\begin{tabular}{|c|c|c|c|c|}
\hline \multirow{2}{*}{$\begin{array}{l}\text { Specimen } \\
\text { Polymerization unit }\end{array}$} & \multicolumn{3}{|c|}{ Wear depth $(\mu \mathrm{m})$} & \multirow{2}{*}{ Statistical category } \\
\hline & Mean (SD) & Median & IQR & \\
\hline \multicolumn{5}{|l|}{ Estenia C\&B } \\
\hline Hyper LII & $5.7(0.9)$ & 5.4 & 0.7 & $\mathrm{k}$ \\
\hline$\alpha$-Light II & $18.5(5.9)$ & 17.8 & 7.5 & 1 \\
\hline Labolight LV-II & $64.2(17.0)$ & 64.7 & 30.4 & $\mathrm{~m}$ \\
\hline \multicolumn{5}{|l|}{ Epricord } \\
\hline Hyper LII & $12.9(3.6)$ & 13.8 & 5.6 & $\mathrm{n}$ \\
\hline$\alpha$-Light II & 18.7 ( 2.9$)$ & 17.5 & 3.6 & o \\
\hline Labolight LV-II & $48.5(5.4)$ & 46.9 & 7.2 & $\mathrm{p}$ \\
\hline
\end{tabular}

$n=8$; SD: Standard deviation; IQR: Interquartile range;

Type 4 gold alloy was used as the antagonist. Statistical category: Different letters indicate that they are statistically different $(p<0.05)$.

Table 6 Height loss results of Type 4 gold alloy antagonist

\begin{tabular}{|c|c|c|c|c|}
\hline \multirow{2}{*}{$\begin{array}{l}\text { Underlying plate specimen } \\
\text { Polymerization unit }\end{array}$} & \multicolumn{3}{|c|}{ Height loss of the gold alloy antagonist $(\mu \mathrm{m})$} & \multirow{2}{*}{ Statistical category } \\
\hline & Mean (SD) & Median & IQR & \\
\hline \multicolumn{5}{|l|}{ Estenia C\&B } \\
\hline Hyper LII & $8.2(3.2)$ & 7.7 & 3.2 & q \\
\hline$\alpha$-Light II & $25.3(12.4)$ & 22.8 & 11.7 & $\mathrm{r}$ \\
\hline Labolight LV-II & $145.2(22.0)$ & 149.3 & 26.8 & $\mathrm{~s}$ \\
\hline \multicolumn{5}{|l|}{ Epricord } \\
\hline Hyper LII & $21.3(2.2)$ & 21.9 & 3.5 & $\mathrm{u}$ \\
\hline$\alpha$-Light II & $5.3(0.9)$ & 5.5 & 1.7 & $\mathrm{t}$ \\
\hline Labolight LV-II & $8.2(2.7)$ & 8.0 & 5.4 & $\mathrm{t}$ \\
\hline
\end{tabular}

$n=8$; SD: Standard deviation; IQR: Interquartile range;

Statistical category: Identical letters indicate that the values are not statistically different $(p>0.05)$.
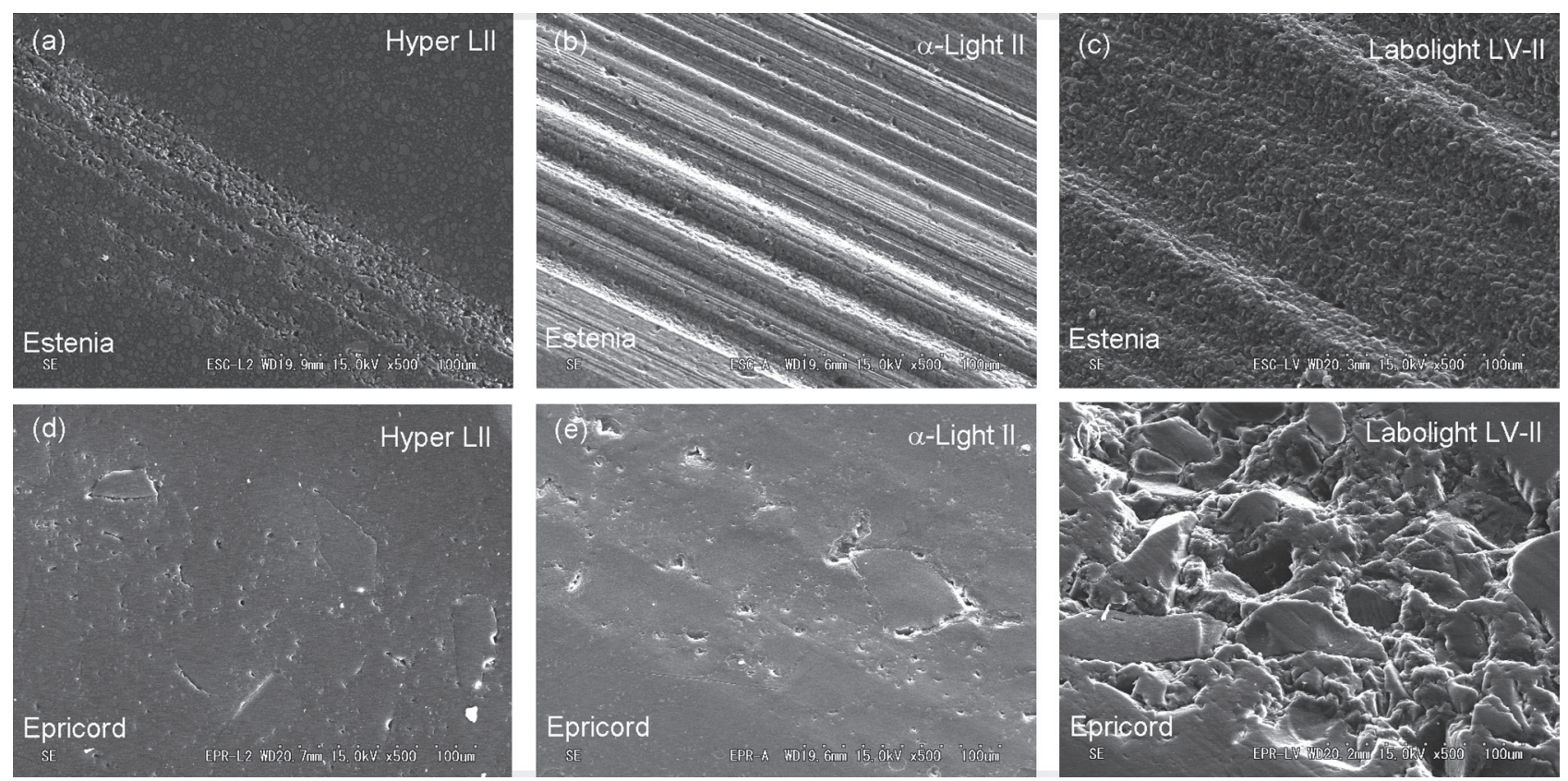

Fig. 3 Worn surfaces of Estenia C\&B polymerized with (a) Hyper LII, (b) $\alpha$-Light II, and (c) Labolight LV-II, and Epricord polymerized with (d) Hyper LII, (e) $\alpha$-Light II, and (f) Labolight LV-II (magnification $\times 500$ ). 

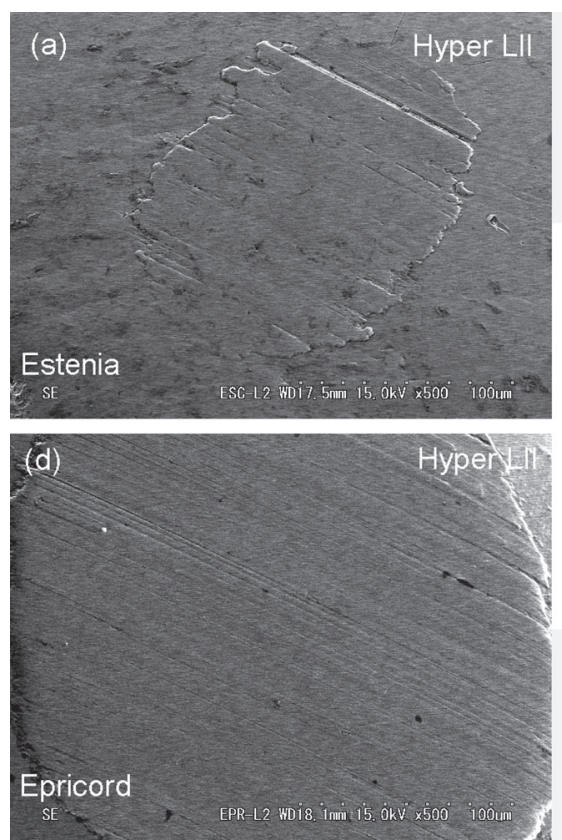
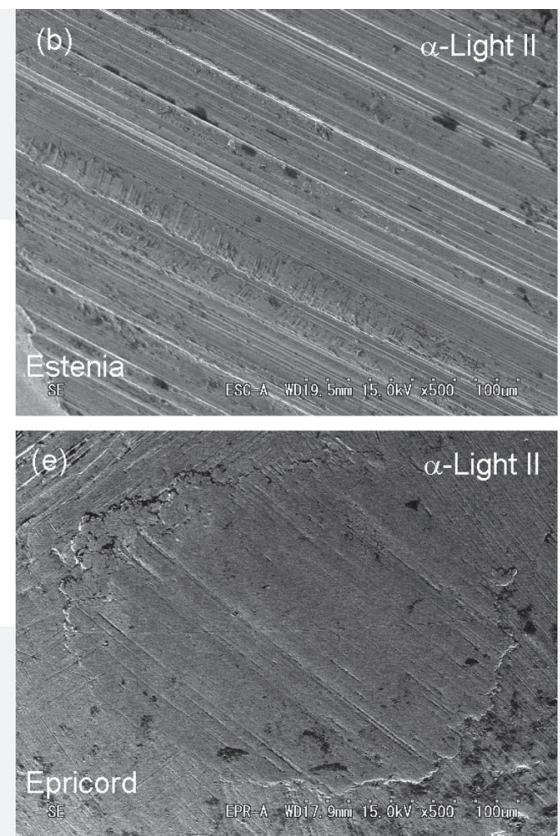
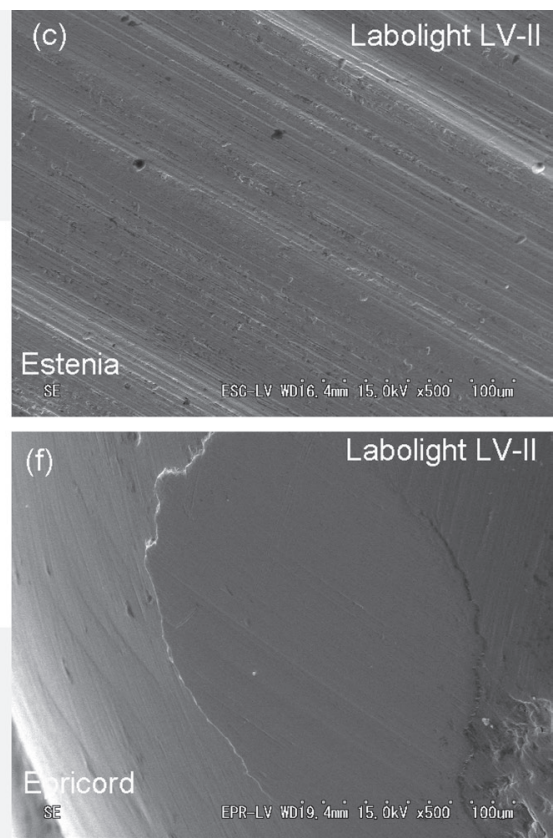

Fig. 4 Worn surfaces of the gold alloy abraded with Estenia C\&B polymerized with (a) Hyper LII, (b) $\alpha$-Light II, and (c) Labolight LV-II, and Epricord polymerized with (d) Hyper LII, (e) $\alpha$-Light II, and (f) Labolight LV-II (magnification $\times 500)$.

$\alpha$-Light II unit was equipped with two fluorescent tubes and a halogen lamp, and its light intensity was 5.7 to 11.3 times that of Labolight LV-II. As shown in Fig. 2, the maximal irradiance of $\alpha$-Light II —due to halogen lamp light source- was more than $40 \mu \mathrm{W} / \mathrm{cm}^{2} \mathrm{~nm}$ in the wavelength range of $450-500 \mathrm{~nm}$. For the polymerization of methacrylate monomers initiated with camphorquinone-amine redox initiation system, Nomoto reported that the optimal wavelength was $470 \mathrm{~nm}$ or a wavelength range of $450-490 \mathrm{~nm}^{32)}$. Hence, the wavelength range within which $\alpha$-Light II achieved its maximal irradiance coincided with the optimal absorption wavelength range for the activation of the initiator used in Estenia C\&B and Epricord composites.

Unlike halogen and fluorescent light sources, the metal halide light source of Hyper LII emitted both ultraviolet and visible lights. Although the spectral irradiance of metal halide light source was maximal within the ultraviolet light range, the second peak was located within the visible light range of $450-490 \mathrm{~nm}$, thus rendering the metal halide light source to be comparable with the halogen light source.

\section{Mechanical properties of indirect composites}

Knoop hardness test results revealed that Estenia C \& B exhibited greater Knoop hardness and flexural strength than Epricord under identical polymerization conditions. This was probably due to a difference in their filler loadings. This finding agreed with other studies ${ }^{8,33}$ in that filler loading played a prominent role in determining the mechanical properties of posterior composites, although the materials and testing methods used were different among the studies.
When polymerized with Hyper LII, which had the highest light intensity, both Estenia C \& B and Epricord exhibited the greatest Knoop hardness and flexural strength. This finding agreed with other studies ${ }^{8,28)}$ in that the light polymerization unit played an important role in determining the post-polymerization properties of composites. Unlike the previous reports ${ }^{8,28)}$, the light intensity levels of polymerization units were measured under specific conditions in this study: simple material compositions and simple light sources. These measures were necessary for a proper assessment of the relation between light intensity of polymerization units and material properties.

\section{Factors which influence the wear of indirect composites} Instead of toothbrush wear test, a sliding wear test was employed in the current study for two reasons. First, the slurry used in sliding wear tests has a composition that mimics saliva and food bolus. In the present study, PMMA was used to mimic food bolus ${ }^{3,34)}$. Secondly, sliding wear tests mimic occlusal contact between maxillary and mandibular posterior dentitions.

The wear of Estenia C \& B was smaller than that of Epricord under identical polymerization conditions. This was probably due to a difference in their filler loadings. This finding agreed with a report by Faria et $a l .{ }^{15)}$ in that there was an inverse correlation between Vickers hardness and wear for indirect composite materials: the higher the hardness, the lower the wear.

The wear behavior of Estenia C \& B and Epricord was also affected by the light polymerization unit. For both materials, polymerization with Hyper LII — which had the highest light intensity - resulted in the lowest 
wear; conversely, polymerization with Labolight LV-II resulted in the highest wear. Results obtained in this study agreed with previous reports in that wear-resistant materials showed excellent mechanical properties ${ }^{8,13,15)}$, and that the mechanical properties and wear resistance of light-polymerized composite materials could be considerably improved by application of high-intensity light sources ${ }^{17,28,29)}$.

Apart from the effect of high-intensity light sources, we speculated that improvement in the double bond conversion of monomers in the composite matrix played a role in improving the wear resistance and properties of composite materials. Peutzfeldt had reported on an evident correlation between light intensity and double bond conversion of bi-functional metahcrylates ${ }^{35}$. In light of the readings and results obtained in this study for light intensity, mechanical properties and wear, it could be suggested that the presence of unreacted double bonds in the matrix negatively affected the wear resistance of composite materials.

\section{Means to improve the wear resistance of indirect composites}

One purpose of the current study was to propose a polymerization method which could improve the wear resistance of composite materials with reduced exposure time. Results of the current study suggested an approach somehow different from that of slow polymerization, in that reduced light exposure time from 180 seconds to 60 seconds with a high-intensity light source could effectively increase wear resistance.

With regard to the approach proposed above, a question may be raised whether comparable wear resistance could be achieved by polymerizing with a lowintensity light unit but for a longer exposure time. The answer to this query could be found in a report by Nomoto et $a l .{ }^{36)}$ in that equivalent degree of monomeric double-bond conversion was achieved if the composite material was irradiated with an equal amount of exposure - the latter being the product of light intensity and exposure time. Based on this finding by Nomoto et $a l .{ }^{36)}$, we speculated that comparable wear resistance might be obtained if the composites were polymerized with Labolight LV-II for a substantially longer time.

\section{Wear of indirect composites and height loss of gold alloy antagonist}

After sliding wear test abrasion, equivalent rankings according to the light source- were obtained for both Estenia C \& B composite (categories $\mathrm{k}, \mathrm{l}$, and $\mathrm{m}$ ) and the gold alloy antagonist (categories $\mathrm{q}, \mathrm{r}$, and $\mathrm{s}$ ). These results suggested a similarity in surface property, especially in terms of wear resistance, between Estenia C\&B composite and age-hardened Type IV gold alloy. These results were also congruent with the results of a previous report ${ }^{37}$, in which the composite material was light- and heat-polymerized.

With respect to ranking by light source, the Epricord composite exhibited a wear behavior different from that of Estenia C\&B after sliding wear test abrasion. In addition, the Epricord specimen polymerized with Labolight LV-II showed a considerably roughened surface after wear test (Fig. 3f). From the SEM images (Figs. 3d-f) and the wear depth and height loss of Epricord-gold alloy specimens (Tables 5 and 6), it was evident that the Epricord material was less wearresistant than the age-hardened Type IV gold alloy. The inferior wear resistance probably stemmed from the exposed splintered filler or matrix particles in the Epricord material as well as the lower wear resistance of the matrix when compared to the gold alloy.

Taking into account the factors which affected the wear resistance of indirect composites and the effect of surface property compatibility between the occlusal surface and antagonist, it is highly recommended that clinicians and dental laboratory technicians exercise both caution and discernment when polymerizing indirect composite materials using laboratory polymerization apparatus.

\section{ACKNOWLEDGMENTS}

This work was supported in part by Grants-in-Aid for Scientific Research, (C) 20592283 and 20592302 (2008-2010), from the Japan Society for the Promotion of Science (JSPS), and by a Grant from the Dental Research Center (2010) and by Sato Fund (2009) from Nihon University School of Dentistry.

\section{REFERENCES}

1) Staffanou RS, Hembree JH, Rivers JA, Myers ML. Abrasion resistance of three types of esthetic veneering materials. J Prosthet Dent 1985; 53: 309-310.

2) Lappalainen R, Yli-Urpo A, Seppa L. Wear of dental restorative and prosthetic materials in vitro. Dent Mater 1989; 5: 35-37.

3) Matsumura H, Leinfelder KF. Localized three-body wear of six types of composite resin veneering materials. J Prosthet Dent 1993; 70: 207-213.

4) Ambjørnsen E, Holland RI. In vitro abrasion of two acrylic veneers. Dent Mater 1994; 10: 107-110.

5) Matsumura H, Leinfelder KF. Three-body wear of four types of light-activated composite resin veneering materials. Quintessence Int 1994; 25: 425-430.

6) Hudson JD, Goldstein GR, Georgescu M. Enamel wear caused by three different restorative materials. J Prosthet Dent 1995; 74: 647-654.

7) Matsumura H, Leinfelder KF, Kawai K. Three-body wear of light-activated composite veneering materials. J Prosthet Dent 1995; 73: 233-239.

8) Freiberg RS, Ferracane JL. Evaluation of cure, properties and wear resistance of Artglass dental composite. Am J Dent 1998; 11: 214-218.

9) Kern M, Strub JR, Lü XY. Wear of composite resin veneering materials in a dual-axis chewing simulator. J Oral Rehabil 1999; 26: 372-378.

10) Tanoue N, Matsumura $H$, Atsuta $M$. Wear and surface roughness of current prosthetic composites after toothbrush/ dentifrice abrasion. J Prosthet Dent 2000; 84: 93-97.

11) Suzuki S, Nagai E, Taira Y, Minesaki Y. In vitro wear of indirect composite restoratives. J Prosthet Dent 2002; 88: 431-436.

12) Fujii K, Ban S, McCabe JF. Tooth brush abrasion of paint-on 
resins for shade modification of crown and bridge resins. Dent Mater J 2003; 22: 244-250.

13) Reich SM, Petschelt A, Wichmann M, Frankenberger R. Mechanical properties and three-body wear of veneering composites and their matrices. J Biomed Mater Res A 2004; 69: 65-69.

14) Heintze SD, Zappini G, Rousson V. Wear of ten dental restorative materials in five wear simulators - Results of a round robin test. Dent Mater 2005; 21: 304-317.

15) Faria AC, Benassi UM, Rodrigues RC, Ribeiro RF, Mattos Mda G. Analysis of the relationship between the surface hardness and wear resistance of indirect composites used as veneer materials. Braz Dent J 2007; 18: 60-64.

16) Jain V, Platt JA, Moore BK, Borges GA. In vitro wear of new indirect resin composites. Oper Dent 2009; 34: 423-428.

17) Murakami M. Surface properties of an indirect composite polymerized with five laboratory light polymerization systems. J Oral Sci 2009; 51: 215-221.

18) Nakazawa M. Color stability of indirect composite materials polymerized with different polymerization systems. J Oral Sci 2009; 51: 267-273.

19) Matsumoto Y, Furuchi M, Koizumi H, Matsumura H. Effect of preliminary irradiation on depth of cure and hardness of a veneering composite. J Oral Sci 2010; 52: 71-75.

20) Matsumoto Y, Furuchi M, Oshima A, Tanoue N, Koizumi H, Matsumura $\mathrm{H}$. Effect of preliminary irradiation on the bond strength between a veneering composite and alloy. Dent Mater J 2010; 29: 84-88.

21) Ekfeldt A, Olio G. Occlusal contact wear of prosthodontic materials. An in vivo study. Acta Odontol Scand 1988; 46: 159-169.

22) O'Neal SJ, Leinfelder KF, Barrett CE. Clinical evaluation of Dentacolor as a posterior veneering agent. J Esthet Dent 1989; 1: 29-33.

23) Bergman B, Nilson H, Andersson M. Dentacolor as veneering material for titanium. A clinical evaluation after 51-72 months. Swed Dent J 1994; 18: 25-28.

24) Matsumura H, Nakamura M, Tanoue N, Atsuta M. Clinical evaluation of an urethane tetramethacrylate-based composite material as a prosthetic veneering agent. J Oral Rehabil 2000; 27: 846-852.

25) Tanoue N, Mori S, Sugawara H, Matsumura H, Koizumi H. One-year clinical evaluation of anterior composite veneered restorations made of the Solidex composite and silver- palladium-copper-gold alloy. Int Chin J Dent 2006; 6: 105-109.

26) Stober T, Dreyhaupt J, Lehnung U, Rammelsberg P. Occlusal wear of metal-free ceramic-filled polymer crowns after 2 years in service. Int J Prosthodont 2008; 21: 161-165.

27) Shiono H, Koizumi H, Hirata M, Ayano M, Nakayama D, Matsumura H. Seven-year clinical evaluation of indirect restorations made of the Estenia composite. Int Chin J Dent 2009; 9: 39-43.

28) Matsumura H, Tanoue N, Atsuta M, Kitazawa S. A metal halide light source for laboratory curing of prosthetic composite materials. J Dent Res 1997; 76: 688-693.

29) Tanoue N, Matsumura H, Atsuta M. Curing depth of a composite veneering material polymerized with seven different laboratory photo-curing units. J Oral Rehabil 1998; 25: $199-203$

30) Hirose H, Kawamoto Y, Kojima T, Sakaguchi S, Kimura K, Saitoh M, Yoshihashi K, Matsumura H, Nishiyama M. Density, polymerization shrinkage, filler content and coefficient of thermal expansion of composite resins for crown and bridge. J J Dent Mater 2006; 25: 62-68.

31) Izumida A, Yoda M, Inagaki R, Toyoda J, Ishibashi M, Kasahara S, Kimura K. Mechanical properties of hard resins for crowns and beidges. J Jpn Prosthodont Soc 2008; 52: 521-528.

32) Nomoto R. Effect of light wavelength on polymerization of light-cured resins. Dent Mater J 1997; 16: 60-73.

33) Chung KH, Greener EH. Correlation between degree of conversion, filler concentration and mechanical properties of posterior composite resins. J Oral Rehabil 1990; 17: 487-494.

34) De Gee AJ, Pallav P, Davidson CL. Effect of abrasion medium on wear of stress-bearing composites and amalgam in vitro. $\mathrm{J}$ Dent Res 1986; 65: 654-658.

35) Peutzfeldt A. Correlation between recordings obtained with a light-intensity tester and degree of conversion of a light-curing resin. Scand J Dent Res 1994; 102: 73-75.

36) Nomoto R, Uchida K, Hirasawa T. Effect of light intensity on polymerization of light-cured composite resins. Dent Mater J 1994; 13: 198-205.

37) Ogino T, Koizumi H, Furuchi M, Murakami M, Matsumura $\mathrm{H}$, Tanoue N. Effect of a metal priming agent on wear resistance of gold alloy-indirect composite joint. Dent Mater J 2007; 26: 201-208. 